\title{
Una rúbrica para la evaluación de textos expositivos
}

\author{
A Rubric to Assess Expository Texts
}

Uma rubrica para avaliação de textos expositivos

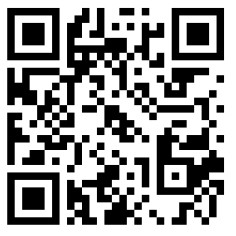

Recibido • Received • Recebido: 10 / 01 / 2019

Corregido • Revised • Revisado: 06 / 07 / 2020

Aceptado $\cdot$ Accepted $\cdot$ Aprovado: 18 / 08 / 2020

Resumen: La formación en competencias comunicativas del futuro personal docente se ha convertido en una necesidad en el Espacio Europeo de Educación Superior (EEES). En este sentido, es fundamental conocer la competencia escritora de las personas docentes en formación $y$, concretamente, sus habilidades para elaborar un texto. Por ello, el objetivo de este artículo de investigación fue la validación de una rúbrica analítica para evaluar textos expositivos escritos por estudiantado universitario. El instrumento ha considerado siete dimensiones generales que se valoran, a partir de una escala de estimación, que va de excelente a deficiente, pasando por bueno y aceptable. Mediante una metodología mixta (cualitativa-cuantitativa), se procedió a la validación del instrumento, en el que inicialmente 12 personas juzgaron, de manera independiente, validaron su contenido y después se realizó su validación estadística con el software Statistical Package for the Social Sciences (SPSS). Se obtuvo la unanimidad de juicio del equipo evaluador, así como una elevada consistencia interna en el instrumento. Por tanto, la rúbrica goza de una adecuada validez de constructo, constatada por la valoración experta, y una alta fiabilidad, lo que justifica su utilidad para analizar y valorar textos expositivos en futuro estudiantado universitario y docentes en formación.

Palabras claves: Educación superior; escritura; evaluación del estudiantado; texto escrito. 
http://doi.org/10.15359/ree.24-3.22

http://www.una.ac.cr/educare

educare@una.ac.cr

\begin{abstract}
Teaching communicative competences to future teachers has become a need for the European Higher Education Area (EHEA). In this regard, it is essential to know the writing competence of the teachers in training and, specifically, their skills when it comes to writing a text. For that reason, this research article aimed to validate an analytical rubric to evaluate expository texts written by university students. The tool has taken into consideration seven general dimensions assessed according to an estimation scale, ranging from excellent to deficient, including good and acceptable. The validation of the tool was carried out using a mixed methodology (quantitative-qualitative), in which initially 12 independent judges validated its content, and then a statistical validation with the statistical package software (SPSS) was conducted. The results were the obtention of the unanimity of judgment among judges and high internal consistency in the tool. Therefore, the rubric has the suitable construct validity, validated by the judges' assessment, and high reliability, which justifies its usefulness in analyzing and assessing expository texts to be written by future university students and teachers in training.
\end{abstract}

Keywords: Higher education; writing; student evaluation; written text.

Resumo: A capacitação em competências comunicativas de futuros docentes se transformou em uma necessidade no Espaço Europeu de Educação Superior (EEES). Nesse sentido, é fundamental conhecer a competência escrita dos docentes em formação e, de fato, suas habilidades para elaborar textos. Por isso, o objetivo deste artigo de pesquisa foi a validação de uma rubrica analítica para avaliar textos expositivos escritos por estudantes universitários. O instrumento utilizado considerou sete dimensões gerais que são avaliadas em uma escala de estimativa que varia de excelente a ruim, passando por bom e aceitável. Com o uso de uma metodologia mista (qualitativa e quantitativa), se procedeu a validação do instrumento, no qual inicialmente 12 pessoas fizeram o julgamento de forma independente, validaram seu conteúdo e depois foi realizada a validação estatística com o software Statistical Package for the Social Sciences (SPSS). Obteve-se a unanimidade no julgamento entre os avaliadores, assim como uma elevada consistência interna no instrumento. Portanto, a proposta possui uma validade adequada de construto, constatada pela avaliação dos juízes e uma alta confiabilidade, o que justifica sua utilização para analisar e avaliar textos expositivos de estudantes universitários e professores em formação.

Palavras-chave: Ensino superior; escrita; avaliação do estudante; texto escrito.

\title{
Introducción
}

La universidad española participa en un proceso de cambio para adaptarse a las demandas del Espacio Europeo de Educación Superior (EEES) en el que está inmersa, asumiendo una reformulación de roles y competencias en el profesorado y estudiantado. El trabajo por competencias demanda una nueva metodología, distinta a la tradicional, que supone, a su vez, el manejo de nuevos sistemas de evaluación (Poblete et al., 2016).

La noción de competencia pretende ser un elemento clarificador y facilitador de una mayor formación interdisciplinar del estudiantado, a la que las instituciones de educación 
http://doi.org/10.15359/ree.24-3.22

superior habrán de reorientar sus enseñanzas (López Ruiz, 2011) para favorecer la empleabilidad mediante una inserción profesional a largo plazo (Verano-Tacoronte et al., 2016). Formar a docentes en competencias exige generar situaciones didácticas para enfrentar al estudiantado a las tareas que deben resolver, vinculadas con problemáticas reales (Díaz-Barriga Arcedo, 2012).

Las competencias pueden ser definidas como:

Un sistema de conocimientos, habilidades y actitudes que son utilizados de modo interactivo en la ejecución oportuna de tareas y en la resolución de problemas más o menos complejos en el marco de una determinada situación y movilizando los recursos y medios disponibles en el ambiente específico en que se opera. (López Ruiz, 2011, p. 285).

En efecto, las competencias explican y describen de qué forma rendimos, pero no por qué rendimos o no. Son necesarias, pero no bastan para entender el rendimiento (Boyatzis, 1982). No obstante, en los diferentes diseños de competencias para la formación universitaria, se enfatizan las competencias comunicativas en cada una de sus destrezas (hablar, escribir, leer, escuchar), consideradas como competencias iniciales básicas para cualquier docente (Perrenoud, 2004; Ruiz-Terroba et al., 2017). Pero en la bibliografía especializada son muy escasos los instrumentos que ilustran acerca de cómo evaluar habilidades de comunicación escrita en estudiantado universitario (Muñoz y Valenzuela, 2015), de ahí la pertinencia de este estudio. Por ello, el objetivo del artículo fue validar una rúbrica para evaluar las habilidades expositivas de futuro personal docente, a sabiendas de que la escritura es una actividad cognitiva compleja y un ámbito imprescindible para la formación integral del estudiantado, así como un aspecto esencial para su futuro personal y profesional (Ruiz-Terroba et al., 2017).

\section{Marco teórico}

\section{Los textos expositivos}

En la formación universitaria, la adquisición de competencias comunicativas es transcendental, por lo cual resulta prioritaria la atención de las dificultades escritoras del estudiantado (Álvarez y Yániz, 2015). Diferentes estudios han percibido la escritura en el contexto de la educación superior como una herramienta clave para el estudiantado, por cuanto le permite acceder a nueva información y elaborar nuevos saberes, en un proceso de transformación del conocimiento académico (Concha et al., 2010; Marinkovich y Córdova, 2014).

El texto expositivo, predominante en el ámbito académico universitario (VillalongaPenna y Hael, 2016) y fuente de aprendizaje básica en los sistemas educativos formales (FloresCarrasco et al., 2017), se usa, no obstante, como sinónimo de texto explicativo o informativo. 
http://doi.org/10.15359/ree.24-3.22

http://www.una.ac.cr/educare

educare@una.ac.cr

Para Álvarez Angulo (2001), exponer, explicar e informar son conceptos muy próximos entre sí, cuya diferencia reside fundamentalmente en su intencionalidad. Mientras que la exposición pretende mostrar o presentar una serie de informaciones, la explicación, además de mostrarlas, busca su comprensión. En la práctica, exposición y explicación van unidas normalmente, puesto que cuando se expone un contenido se pretende hacerlo de forma que se entienda y llegue a su público destinatario, motivo por el cual Álvarez-Angulo opta por la denominación de textos expositivo-explicativos.

El texto expositivo-explicativo persigue expresar información o ideas con la intención de mostrar, explicar o hacer que sean más comprensibles dichas informaciones (Álvarez, 1993; Álvarez Angulo y Ramírez Bravo, 2011). En este sentido, el texto expositivo contiene elementos sustantivos del texto argumentativo, el cual desempeña un papel fundamental en el acceso al conocimiento disciplinar y en el proceso de alfabetización académica (Córdova Jiménez et al., 2016).

Las principales marcas lingüísticas y textuales que incluye un texto expositivo pueden ordenarse en tres niveles (Álvarez Angulo 2001; Álvarez-Angulo y Ramírez Bravo, 2011):

1. Nivel textual: recursos tipográficos (p. ej., tipo de letra); formas supralingüísticas (p. ej., títulos); uso endofórico de deícticos (anafóricos o catafóricos); abundancia de conectores lógicos (p. ej., adición); fórmula de cierre (resumen o conclusión); definiciones, citas y referencias, descripciones, formulación de hipótesis, justificaciones causales, etc.; escaso empleo de valores estilísticos y ausencia en la variedad de matices (pretensión de objetividad y de universalidad).

2. Nivel oracional: son frecuentes las oraciones simples y las compuestas coordinadas, yuxtapuestas y subordinadas sustantivas, adjetivas y adverbiales; preferencia por las construcciones lógicas sobre las psicológicas (sujeto-verbo-complemento); reformulaciones (paráfrasis), ejemplificaciones, comparaciones o enumeraciones; aposiciones explicativas (p. ej., inciso explicativo); predominio del presente y el futuro de indicativo; abundancia de verbos estáticos y cópula ser; formas verbales no personales o impersonales.

3. Nivel léxico: en general, el léxico es monosemántico y denotativo, ya que se persigue la claridad, la precisión y el rigor. Son frecuentes, por tanto, las siguientes formas lingüísticas: la adjetivación específica y pospuesta; los sustantivos abstractos o concretos; los tecnicismos; los términos compuestos, los derivados y las siglas; y, finalmente, abundan las marcas de modalización o los modalizadores (p. ej., los modalizadores asertivos para indicar la veracidad o falsedad de un enunciado). 
http://doi.org/10.15359/ree.24-3.22

\section{La rúbrica: un instrumento útil para la evaluación de textos}

La consideración de la evaluación como la emisión de juicios acerca del grado en que un escrito cumple con las características esperadas de un buen texto (Beyreli y Ari, 2009) no anula el problema de la subjetividad, dada la imposibilidad de consensuar criterios específicos comúnmente aceptados (Huot y O'Neill, 2009). Este hecho aconseja crear instrumentos de evaluación operativos que permitan evaluar el constructo de la escritura y ayuden a minimizar las discrepancias entre quienes los juzgan. No en vano, el éxito de un procedimiento evaluativo depende, fundamentalmente, de que el instrumento que se maneja mida con exactitud lo que se desea medir (Ibáñez, 2012).

En este escenario, las rúbricas, que establecen criterios y estándares mediante una escala en la que se establecen diferentes niveles de habilidad (Cano, 2015; Verano-Tacoronte et al., 2016), se convierten en un recurso útil para fomentar el aprendizaje, en la medida en que gran cantidad de estudiantes llegan a interiorizar los criterios de evaluación de la rúbrica, asumiéndolos como propios e incluso usándolos para su autoevaluación (Ruiz-Terroba et al., 2017). Además, las rúbricas son oportunas para evaluar tareas en las que no se demandan respuestas correctas o incorrectas en sentido estricto (Díaz-Barriga Arceo y de la Cruz, 2011).

Conviene, no obstante, diferenciar entre rúbricas holísticas y analíticas (Anguiano López Paliza y Velasco Ariza, 2012; Verano-Tacoronte et al., 2016). Las primeras analizan de forma global el producto evaluado, asignando una sola puntuación a la totalidad de rasgos establecidos. En este tipo de rúbrica no hay retroalimentación en el alumnado, ya que no se determinan los detalles sobre puntos fuertes y débiles. Las rúbricas analíticas, sin embargo, ofrecen una escala de valoración descriptiva por rasgos o componentes del producto evaluado, de forma que puedan evaluarse de manera separada y luego proceder a la suma de cada puntuación para obtener la calificación final. Evidentemente, su elaboración precisa de una mayor inversión temporal y ofrece, además, una retroalimentación al estudiantado, ya que se permite construir un listado de fortalezas y debilidades de cada aprendiz que, posteriormente, posibilitará al ente formador diseñar un plan de mejora (Muñoz y Valenzuela, 2015). A este efecto, se ha optado en este estudio por la rúbrica analítica.

\section{Metodología}

\section{El diseño de la rúbrica}

La elaboración de esta rúbrica (ver Apéndice A) se hizo considerando las dimensiones generales de la evaluación de la producción escrita de acuerdo con las características fundamentales que debe poseer el texto expositivo (véase Álvarez, 1993; Álvarez Angulo, 2001; Álvarez-Angulo y Ramírez Bravo, 2011) y tomando como base la abundante bibliografía sobre 
http://doi.org/10.15359/ree.24-3.22

http://www.una.ac.cr/educare

educare@una.ac.cr

confección y diseño de rúbricas. Los pasos seguidos para su construcción fueron los siguientes: a) definición del constructo a evaluar; b) fijación de metas y objetivos; c) establecimiento de dimensiones y rasgos; d) fijación de criterios de evaluación; e) definición de los términos que subyacen al instrumento; f) creación de la escala valorativa; y g) validación de la rúbrica. A continuación, se detalla cada etapa.

La rúbrica final contó con tres versiones previas. En la primera, el equipo experto matizó las dimensiones propuestas, así como la escala de valoración. En la segunda, se establecieron las dimensiones definitivas y se incluyó una especificación de los rangos. En la tercera, se incorporaron selectivamente todas las sugerencias de matiz del equipo expertos, hasta alcanzar el consenso. Sirva como ejemplo un cambio referido al lenguaje empleado en la definición de uno de los indicadores (3.1): El texto cumple íntegramente con su finalidad: transmitir, exponer o explicar información, en lugar de utilizar el adverbio sistemáticamente.

\section{El constructo}

Los futuros cuerpos docentes han ser competentes comunicativamente, deben dominar numerosos recursos comunicativos (verbales/no verbales) para desarrollar con eficacia su actividad profesional. Por ello, el constructo de la rúbrica incluye aquellas habilidades que el estudiantado necesita para escribir un texto expositivo de acuerdo con la bibliografía especializada: a) estar perfectamente organizado y mostrar una estructura clara, ordenada y coherente (estructura textual); b) estructurarse en tres partes fundamentales (introducción, desarrollo y conclusión) (organización textual) y adecuarse a las propiedades fundamentales básicas (adecuación, coherencia, cohesión y corrección); c) cumplir con su objetivo principal: transmitir, exponer o explicar información (finalidad); d) ser totalmente objetivo, de lo contrario no podría ser un texto expositivo (objetividad); e) no ignorar el tema sobre el que se debe escribir y atender siempre al tópico principal (tema); f) tener en cuenta al receptor (audiencia); y g) no eludir el uso de marcas lingüísticas de distinto tipo. En este sentido, se han considerado tres clases de marcas lingüísticas: textuales, oracionales y léxicas.

Messick (1996) ha señalado seis aspectos fundamentales para otorgar validez de constructo: contenido (relevancia de contenido y representatividad del conocimiento y las competencias evaluadas), generalidad (alcance conque la interpretación de las calificaciones pueden ser aplicadas a grupos, tareas, momentos, etc.), externalidad (la relación de la puntuación con otras medidas relevantes para el constructo que también han sido evaluadas: otras rúbricas, evaluaciones finales, pruebas estandarizadas o test de conocimientos previos; relevancia y utilidad de la rúbrica para su propósito), estructuralidad (los criterios de evaluación y el sistema de puntuación de la rúbrica poseen una lógica y racionalidad basada en lo que se quiere evaluar; para lo cual algunos grupos investigadores utilizan el análisis factorial o la evaluación, por personal experto, de las orientaciones y criterios de la rúbrica); sustantividad 
http://doi.org/10.15359/ree.24-3.22

(fundamentos teóricos y empíricos de la consistencia en las respuestas que refleja el proceso de pensamiento utilizado por personal experto en el campo) y consecuencias (evidencias sobre los efectos perseguidos y no perseguidos de la interpretación de la evaluación; valoración de cualquier tipo de consecuencia negativa para individuos o grupos).

\section{Meta y objetivos}

La finalidad principal de este trabajo fue construir un instrumento (rúbrica) válido para evaluar la competencia expositiva del estudiantado. Los objetivos concretos para determinar ese nivel de habilidad se establecieron de acuerdo con las dimensiones previamente señaladas para la confección de la rúbrica. Por tanto, el estudiantado más competente comunicativamente en exposición escrita sería aquel que construyese un texto expositivo que se ajuste a la dimensión de excelente, considerada en la rúbrica que se presenta.

\section{Participantes}

Inicialmente la rúbrica fue evaluada por jueces y juezas independientes. Se diseñó un metainstrumento ad hoc, que fue proporcionado (vía mail o personalmente) a un total de 12 personas expertas investigadoras en expresión escrita ( 6 docentes de universidades de didáctica de la lengua, pertenecientes a 3 universidades españolas, y 6 docentes de universidades de lingüística de otras 4 universidades españolas) para que determinasen la validez de su contenido. Su colaboración fue anónima y el objetivo fue valorar diferentes aspectos: a) pertinencia de las dimensiones e indicadores; b) ubicación e importancia de cada uno de los indicadores; c) adecuación de los rangos establecidos para cada indicador; d) precisión del lenguaje utilizado.

\section{Dimensiones y rasgos por evaluar}

Las dimensiones que el instrumento "Rúbrica para la evaluación de textos expositivos" (ver Apéndice A) contempla se corresponden con las características fundamentales que debe poseer un texto expositivo escrito, de acuerdo con la bibliografía especializada. Desde esta perspectiva, las dimensiones y los rasgos a evaluar fueron los siguientes:

1. Estructura textual: claridad, ordenación y coherencia.

2. Organización textual: introducción, desarrollo y conclusión, y propiedades textuales básicas (adecuación, coherencia, cohesión y corrección).

3. Finalidad: transmitir, explicar y exponer información.

4. Objetividad: ser íntegramente objetivo. 
http://doi.org/10.15359/ree.24-3.22

http://www.una.ac.cr/educare

educare@una.ac.cr

5. Tema: girar en torno a un tópico principal.

6. Audiencia: tener en cuenta al público receptor en todo momento.

7. Marcas lingüísticas:

a) Textuales (recursos tipográficos, conectores lógicos, deícticos y formas supralingüísticas).

b) Oracionales(oracionessimplesocompuestas;construccioneslógicas, reformulaciones, aposiciones explicativas, verbos estáticos).

c) Léxicas (adjetivos especificativos, sustantivos abstractos o concretos, tecnicismos, términos compuestos, derivados o siglas, modalizadores de tipo asertivo, etc.).

Un aspecto no contemplado en la rúbrica es la adecuación del contenido en el texto que se evalúa. Por ello, conviene aclarar que la adecuación del contenido disciplinar precisa también ser revisada en las producciones de los futuros cuerpos docentes, a la luz de los consensos propios de cada disciplina.

\section{Los criterios de evaluación}

Los criterios de evaluación identifican las dimensiones de ejecución del instrumento (Tierney y Simon, 2004). Al respecto, es preciso definir los elementos que posteriormente serán evaluados para determinar el éxito en la ejecución de un texto expositivo por parte de los aprendices. Al respecto, existen estudios que ofrecen recomendaciones de interés (Brualdi, 2002): a) enlistar los aspectos importantes del producto; b) limitar el número de elementos para que estos sean observables; b) expresar los criterios en términos de comportamientos visibles; c) evitar el uso de términos ambiguos; d) colocar los elementos en el orden en el que probablemente se observen. De acuerdo con estas ideas, se establecieron siete criterios de evaluación conforme a las siete dimensiones de que consta la rúbrica diseñada: i) el texto presenta una estructura clara, ordenada y coherente; ii) el texto se organiza en tres partes fundamentales (introducción, desarrollo y conclusión) y se escribe de acuerdo con las propiedades textuales básicas; iii) la finalidad del texto es la de transmitir, explicar o exponer información; iv) el texto es totalmente objetivo; v) el texto no se desvía del tema principal en ningún momento y se centra en él; vi) el texto se adecua al público receptor en todo momento; vii) en el texto se evidencian numerosas marcas lingüísticas de tipo textual, oracional y léxico.

\section{Definición de los términos}

Los conceptos sobre los que se ha confeccionado la rúbrica provienen de diferentes textos (Álvarez, 1993; Álvarez Angulo, 2001; Álvarez-Angulo y Ramírez Bravo, 2011; Cassany, 1997). Estos mencionan tanto los términos referidos para los textos expositivos (estructura y organización textual, finalidad, objetividad, tema, audiencia y marcas) como los descritos para las propiedades textuales básicas (adecuación, coherencia, cohesión y corrección). 
http://doi.org/10.15359/ree.24-3.22

\section{Elaboración de la escala valorativa}

La rúbrica se diseñó de acuerdo con unos niveles de desempeño en la realización de un texto expositivo de calidad. La escala de valoración inicialmente tuvo cuatro niveles: a) excelente (100\%-90\%); b) bueno (80-70\%); c) aceptable (60-50\%); y d) deficiente (40-0\%). Posteriormente, esta escala se modificó, según se indica en el siguiente apartado, tras ser sometida a juicio de personas expertas: a) excelente (100-85\%); b) bueno (84-66\%); c) aceptable (65-46\%) y d) deficiente (45-0\%). En última instancia y con el objeto de ser codificada fácilmente para su validación estadística, dicha escala se vio sometida a una tercera modificación; esta vez, en códigos de un solo dígito numérico: excelente (1); bueno (2); aceptable (3) y deficiente (4). Igualmente, cada nivel de la rúbrica se subdividió en cuatro apartados de acuerdo con la numeración de cada dimensión (ver Apéndice A).

En definitiva, las siete dimensiones de la rúbrica se valoran a partir de una escala de estimación cuya gradación va de excelente a deficiente, pasando por bueno y aceptable. A cada dimensión se le puede asignar un valor, esto es, una puntuación que oscila entre el 100\% y el $0 \%$, referida al cumplimiento de la valoración descriptiva de cada dimensión.

\section{Resultados}

\section{Del juicio de personas expertas}

Se procedió a la validación del contenido de la rúbrica a través del juicio de personas expertas y se obtuvieron 12 respuestas ( 2 no emitieron juicio), en las que se aportaron sugerencias fundamentadas para la mejora, que se incorporaron a la rúbrica. Una vez modificada, se volvió a enviar dos veces más el instrumento a las doce personas expertas, hasta alcanzar la unanimidad de juicio entre el equipo evaluador.

\section{Del análisis estadístico}

Además del juicio experto, la rúbrica fue evaluada estadísticamente. En efecto, para determinar su fiabilidad se realizaron distintas pruebas estadísticas con el software Statistical Package for the Social Sciences (SPSS), versión 20. El coeficiente global del instrumento ha obtenido un alfa de Cronbach de 0.90 , como se puede apreciar en la Tabla 1 . Si se tiene en cuenta como norma general que el valor de coherencia viene dado por la obtención de un índice igual o superior a 0.70 , se puede afirmar que el instrumento posee una elevada consistencia interna (un 90\%) y, con ello, una alta fiabilidad. 
http://doi.org/10.15359/ree.24-3.22

http://www.una.ac.cr/educare

educare@una.ac.cr

Tabla 1: Estadístico de fiabilidad del instrumento

\begin{tabular}{cc}
\hline Alfa de Cronbach & N elementos \\
\hline .903 & 10 \\
\hline
\end{tabular}

Nota: Elaboración propia.

Asimismo, se procedió a estudiar la consistencia interna total mediante la prueba de las dos mitades. Los resultados del índice a de Cronbach y de los coeficientes de Guttman-Flanagan y de Spearman-Brown fueron los siguientes (ver Tabla 2):

Tabla 2: Estadísticos de fiabilidad del instrumento por el procedimiento de las dos mitades

\begin{tabular}{|l|l|l|c|}
\hline \multicolumn{1}{|c|}{ Alfa de Cronbach } & Parte 1 & Valor & .871 \\
\hline & & N de elementos & $5(\mathrm{a})$ \\
\hline & Parte 2 & Valor & .777 \\
\hline & & N de elementos & $4(\mathrm{~b})$ \\
\hline & N total de elementos & & 10 \\
\hline Correlación entre formas & & .778 \\
\hline Coeficiente de Spearman-Brown & Longitud igual & & .875 \\
\hline \multicolumn{2}{|l|}{} & .876 \\
\hline Dos mitades de Guttman & Longitud desigual & & .857 \\
\hline
\end{tabular}

Nota: Elaboración propia.

Como se puede observar, los valores de todos los indicadores oscilan entre los extremos del intervalo topológico [0.77-0.87], lo que demuestra la coherencia y fiabilidad de la rúbrica evaluada.

\section{Conclusiones}

Las competencias comunicativas (orales/escritas), indisociables del desempeño docente, constituyen un tópico relevante de la investigación actual y, en el contexto del EEES, se perciben como una competencia clave para la empleabilidad del estudiantado egresado universitario, máxime cuando se sabe que no poca cantidad de docentes tienen problemas para comunicar o comunicarse (Camacho Pérez y Sáenz Barrio, 2000). Esto constituye un desafío para el profesorado universitario, preocupado por la búsqueda de recursos que den respuesta a cómo enseñar-aprender competencias profesionales (trabajo en equipo, aprendizaje autónomo, habilidades comunicativas...). 
Por ello, el objetivo de este estudio fue demostrar la fiabilidad de un instrumento (rúbrica) para evaluar textos expositivos producidos por estudiantado universitario, a fin de contar con un recurso en español que permita medir estas habilidades escritoras del futuro profesorado. Resulta obvio el interés creciente entre el profesorado acerca del empleo de rúbricas para evaluar los aprendizajes universitarios, por cuanto permiten, de una parte, favorecer el desarrollo de las competencias a alcanzary, de otra, mejorar los procesos de su valoración, al objetivar los criterios de medida orientando al estudiantado con respecto a los niveles de ejecución deseables y disminuyendo el posible sesgo entre quienes les evalúan (Verano-Tacoronte et al., 2016).

Algunos estudios han demostrado que existe una correlación positiva entre las habilidades expositivas y el desempeño docente (Ruiz-Terroba et al., 2017), lo que aconseja disponer de recursos que permitan conocer hacia dónde dirigir las estrategias de enseñanza-aprendizaje en el aula con el estudiantado universitario (futuro personal docente).

Como se ha indicado, la validez de contenido del instrumento, de acuerdo con criterios de representatividad y relevancia de los ítems, la determinó un grupo experto de investigación. Pero también se comprobó estadísticamente su alto nivel de fiabilidad y consistencia interna. En consecuencia, se ofrece un instrumento válido y confiable, que puede ser utilizado para conocer las habilidades expositivas de docentes en formación.

No obstante las principales limitaciones del estudio, ya señaladas en la bibliografía especializada sobre el diseño y la validación de rúbricas, se pueden concretar en las siguientes: a) la inversión temporal que requiere; b) la pertinencia de un adecuado entrenamiento para su manejo; c) la necesidad de personal calificado.

Mejorar el diseño de esta rúbrica es una tarea pendiente en la que se pretende implicar al estudiantado, con el fin de convertirla en un recurso útil para fomentar el aprendizaje e incrementar su competencia escritora.

\section{Declaración de Material complementario}

Este artículo tiene disponible como material complementario:

- La versión preprint del artículo en https://doi.org/10.5281/zenodo.3364195

\section{Referencias}

Álvarez, M. (1993). Tipos de escrito Il: Exposición y argumentación. Arco-Libros.

Álvarez, M. y Yániz, C. (2015). Writing practices in spanish universities. Cultura y Educación, 27(3), 594-628. https://doi.org/10.1080/11356405.2015.1072356

Álvarez Angulo, T. (2001). Textos expositivo-explicativos y argumentativos. Octaedro. 
http://doi.org/10.15359/ree.24-3.22

http://www.una.ac.cr/educare

educare@una.ac.cr

Álvarez Angulo, T. y Ramírez Bravo, R. (2011). Características de un texto expositivo. En I. García Parejo (Coord.), Escribir textos expositivos en el aula. Fundamentación teórica y secuencias didácticas para diferentes niveles (pp. 35-47). Graó.

Anguiano López Paliza, M. L. y Velasco Ariza, V. (2012). La construcción y evidencias de validez de una rúbrica analítica para la evaluación de ensayos. Revista de Evaluación Educativa, 1(2) 1-21. https://docplayer.es/22695909-La-construccion-y-evidencias-de-validez-deuna-rubrica-analitica-para-la-evaluacion-de-ensayos.html

Beyreli, L. y Ari, G. (2009). The use of analytic rubric in the assessment of writing performance -inter-rater concordance study-. Educational Sciences: Theory and Practice, 9(1), 105-125. https://files.eric.ed.gov/fulltext/EJ837777.pdf

Boyatzis, R. E. (1982). The competent manager: A model for effective performance. Johm Wiley \& Sons.

Brualdi, A. (2002). Implementing performance assessment in the classroom (Cap. 1). En C. Boston (Ed.), Undestanding scoring rubrics: A guide for teachers (pp. 8-11). ERIC.

Camacho Pérez, S. y Sáenz Barrio, Ó. (2000). Técnicas de comunicación eficaz para profesores y formadores. Marfil.

Cano, E. (2015). Las rúbricas como instrumento de evaluación de competencias en educación superior: ¿Uso o abuso? Profesorado 19(2), 265-280. https://www.ugr.es/ recfpro/ rev192COL2.pdf

Cassany, D. (1997). Describir el escribir. Paidós.

Concha, S., Aravena, S., Coloma, C. J. y Romero, V. (2010). Escritura expositiva en tres niveles de escolaridad: Coherencia y dominio de recursos lingüísticos. Literatura y Lingüistica, 21, 7592. https://doi.org/10.4067/S0716-58112010000100007

Córdova Jiménez, A., Velásquez Rivera, M. y Arenas Witker, L. (2016). El rol de la argumentación en el pensamiento crítico y en la escritura epistémica en biología e historia: Aproximación a partir de las representaciones sociales de los docentes. Alpha, 43, 39-55. https://doi. org/10.4067/S0718-22012016000200004

Díaz-Barriga Arceo, F. (2012). Reformas curriculares y cambio sistémico: Una articulación ausente pero necesaria para la innovación. Revista Iberoamericana de Educación Superior, 3(7), 2340. https://doi.org/10.22201/iisue.20072872e.2012.7.63

Díaz-Barriga, F.y De la Cruz, G. (2011). Las rúbricas en la evaluación de competencias y aprendizaje complejo: Sus alcances y restricciones en educación superior. En K. Buján Vidales, I. Rekalde Rodríguez y P. Aramendi J (Coords.), La evaluación de competencias en educación superior. Las rúbricas como instrumento de evaluación (pp. 13-35). Eduforma.

Flores-Carrasco, P. G., Díaz-Mujica, A. y Lagos-Herrera, I.E. (2017). Comprensión de textos en soporte digital e impreso y autorregulación del aprendizaje en grupos universitarios de estudiantes de educación. Revista Electrónica Educare, 21(1), 1-17. https://doi.org/10.15359/ree.21-1.7

\begin{tabular}{l|ll}
\hline 12 & Elisabeth Melguizo-Moreno y José Luis Gallego-Ortega
\end{tabular}

Los artículos de la Revista Electrónica Educare del Centro de Investigación y Docencia en Educación de la Universidad Nacional, Costa Rica, se comparten bajo términos de la Licencia Creative Commons: Reconocimiento, No Comercial, Sin Obra Derivada 3.0 Costa Rica. Las autorizaciones adicionales a las aquí delimitadas se pueden obtener en el correo: educare@una.cr 
http://doi.org/10.15359/ree.24-3.22

Huot, B. y O’Neill, P. (2009). Assessing writing. A critical sourcebook. Bedford/St. Martin's.

Ibáñez, R. (2012). La comprensión del discurso escrito: Una propuesta teórico-metodológica para su evaluación. Revista Signos, 45(78), 20-43. https://doi.org/10.4067/S0718$\underline{09342012000100002}$

López Ruiz, J. I. (2011). Un giro copernicano en la enseñanza universitaria: Formación por competencias. Revista de Educación, 356, 279-301. 10-4438/1988-592X-RE-2010-356-040

Marinkovich, J. y Córdova, A. (2014). La escritura en la universidad: Objeto de estudio, método y discursos. Revista Signos, 47(84), 40-63. https://doi.org/10.4067/S0718$\underline{09342014000100003}$

Messick, S. (1996). Validity of Performance Assessments. En G. W. Phillips (Ed.), Technical issues in large-scale performance assessment (pp. 1-18). NCES-National Center for Education Statistics.

Muñoz, C. y Valenzuela, J. (2015). Características psicométricas de una rúbrica para evaluar expresión escrita a nivel universitario. Formación Universitaria, 8(6), 75-84. https://doi. org/10.4067/S0718-50062015000600010

Perrenoud, P. (2004). Diez nuevas competencias para enseñar. Graó.

Poblete, M., Bezanilla, M. J., Fernández-Nogueira, D. y Campo, L. (2016). Formación del docente en competencias genéricas: Un instrumento para su planificación y desarrollo. Educar, 52(1), 71-91. https://doi.org/10.5565/rev/educar.713

Ruiz-Terroba, R., Vázquez Cano, E. y Sevillano-García, M. L. (2017). La rúbrica de evaluación de la competencia en expresión escrita. Percepción del alumnado sobre su funcionalidad. Ocnos, 16(2), 107-117. https://doi.org/10.18239/ocnos 2017.16.2.1349

Tierney, R. y Simon, M. (2004). What's still wrong with rubrics: Focusing on the consistency of performance criteria across scale levels. Practical Assessment, Research y Evaluation, 9(2), 1-7. https://doi.org/10.7275/jtvt-wg68

Verano-Tacoronte, D., González-Betancor, S. M., Bolívar-Cruz, A., Fernández-Monroy, M. y GalvánSánchez, I. (2016). Valoración de la competencia de comunicación oral de estudiantes universitarios a través de una rúbrica fiable y válida. Revista Brasileira de Educação, 21(64), 39-60. https://doi.org/10.1590/S1413-24782016216403

Villalonga-Penna, M.-M. y Hael, M.-V. (2016). Leer en psicología: ¿Qué elementos de los textos académicos reconocen los estudiantes de un curso avanzado? Revista lberoamericana de Educación Superior, 7(20), 157-171. https://www.ries.universia.unam.mx/index.php/ries/ article/view/205 
http://doi.org/10.15359/ree.24-3.22

http://www.una.ac.cr/educare

educare@una.ac.cr

\begin{tabular}{|c|c|c|c|c|c|c|c|}
\hline \multicolumn{8}{|l|}{$\frac{\bar{b}}{\frac{\pi}{\sigma}}$} \\
\hline 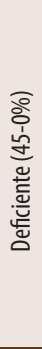 & 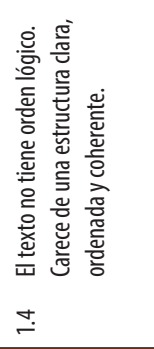 & 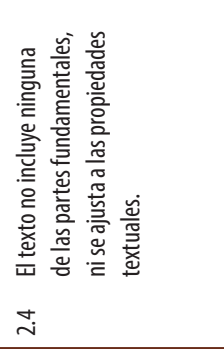 & 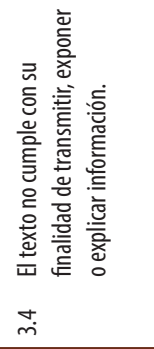 & 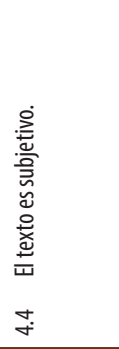 & 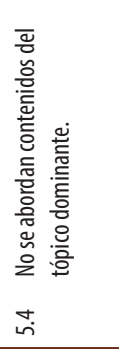 & 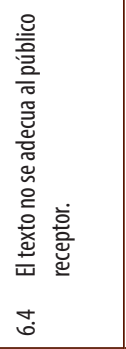 & 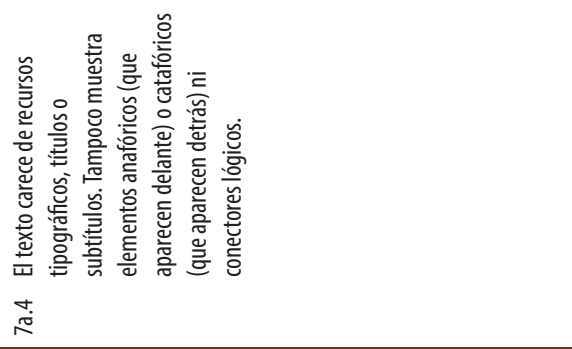 \\
\hline 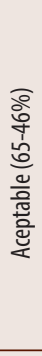 & 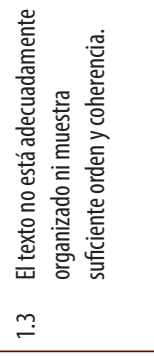 & 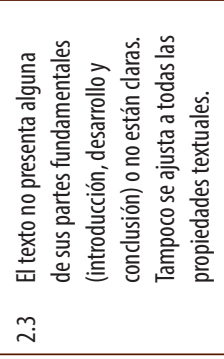 & 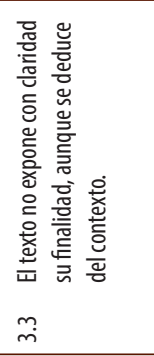 & 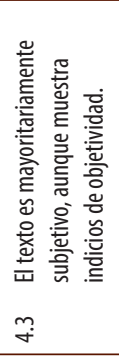 & 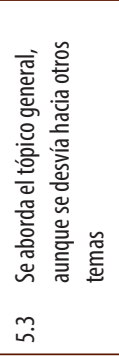 & 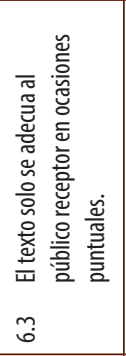 & 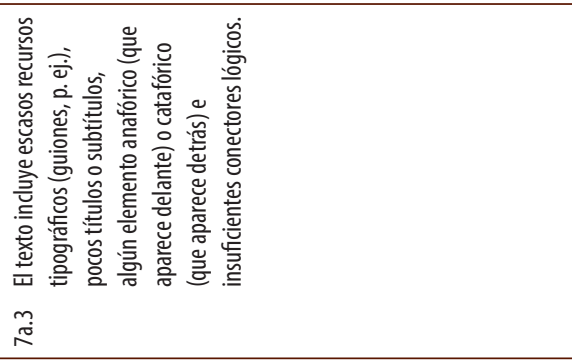 \\
\hline 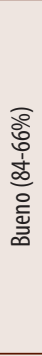 & 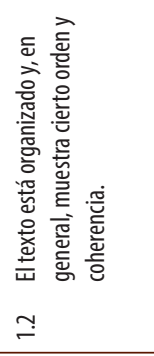 & 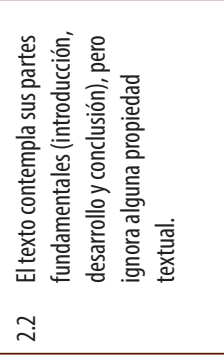 & 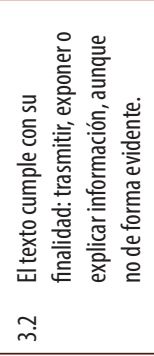 & 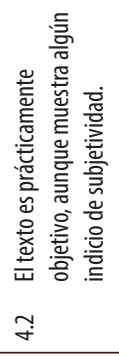 & 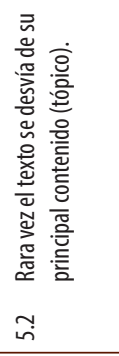 & 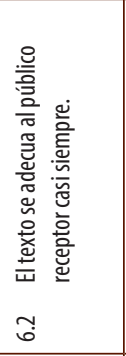 & 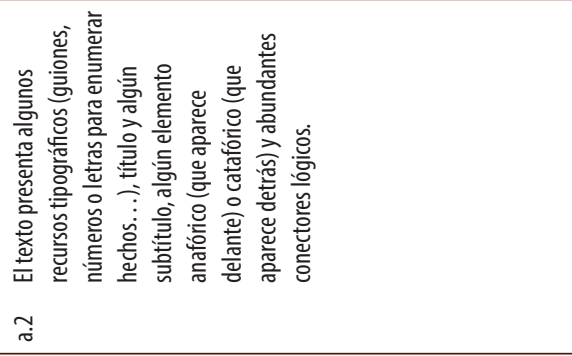 \\
\hline 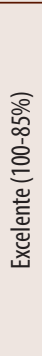 & 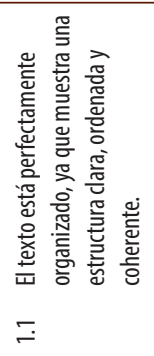 & 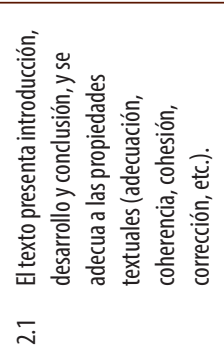 & 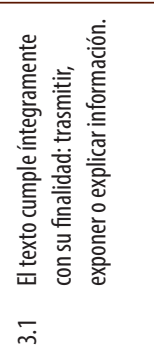 & 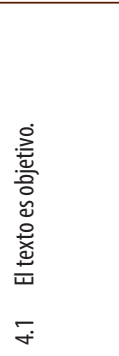 & 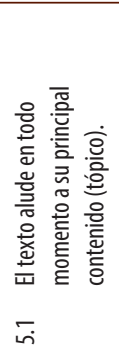 & 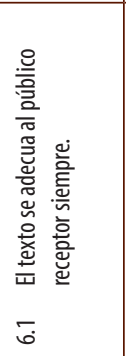 & 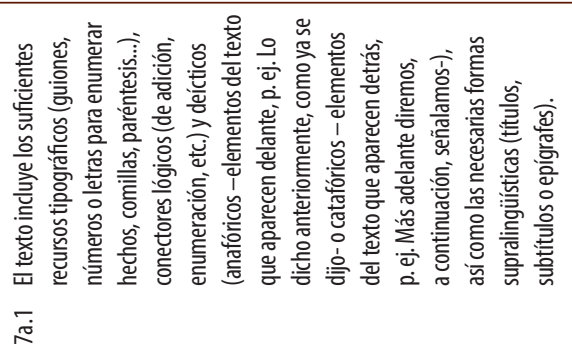 \\
\hline 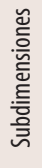 & & & & & & & 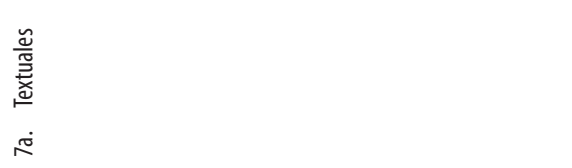 \\
\hline 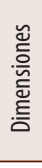 & 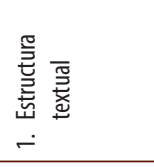 & 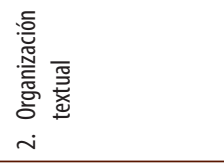 & 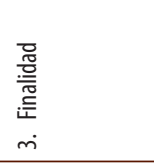 & 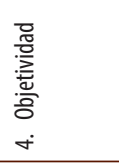 & $\begin{array}{l}\text { 莺 } \\
\text { in }\end{array}$ & 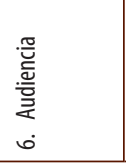 & 密 \\
\hline
\end{tabular}




\begin{tabular}{|c|c|c|}
\hline$\frac{\text { 응 }}{\frac{0}{2}}$ & & \\
\hline & 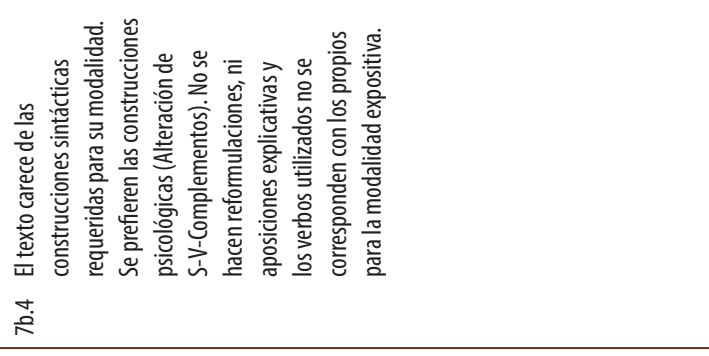 & 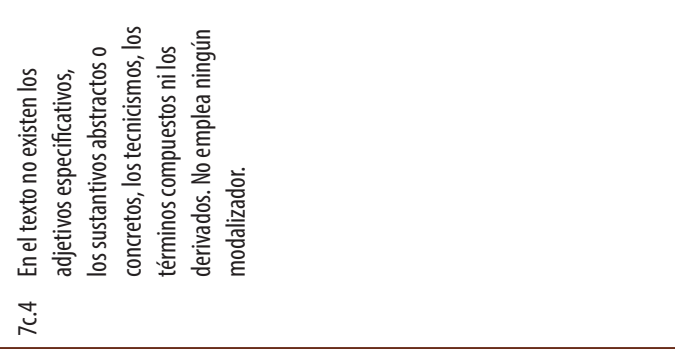 \\
\hline 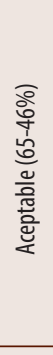 & 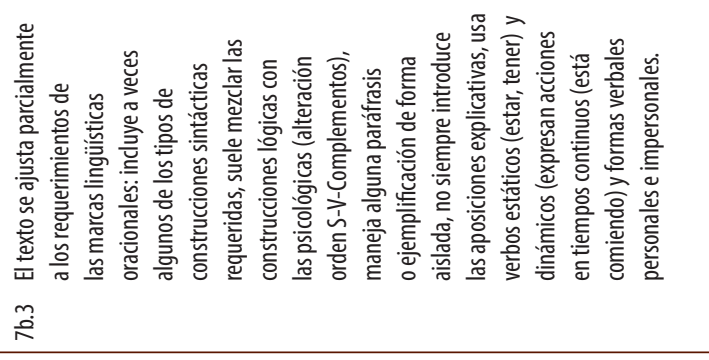 & 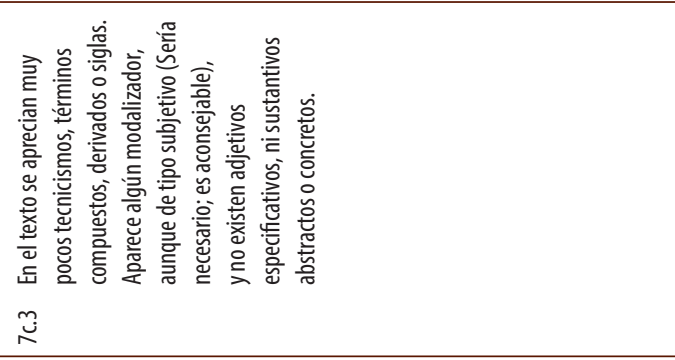 \\
\hline 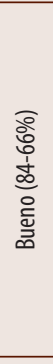 & 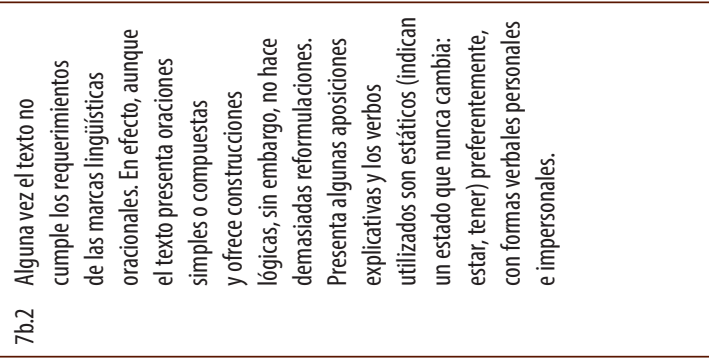 & 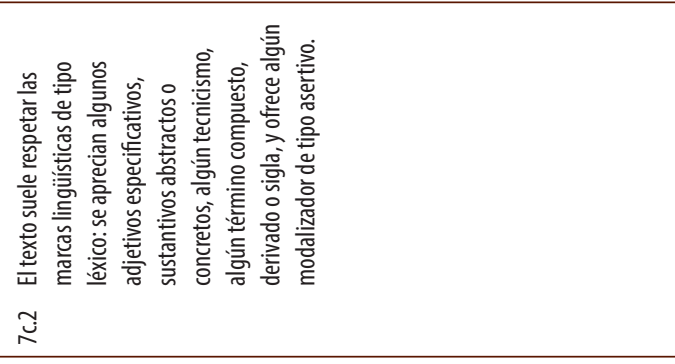 \\
\hline & 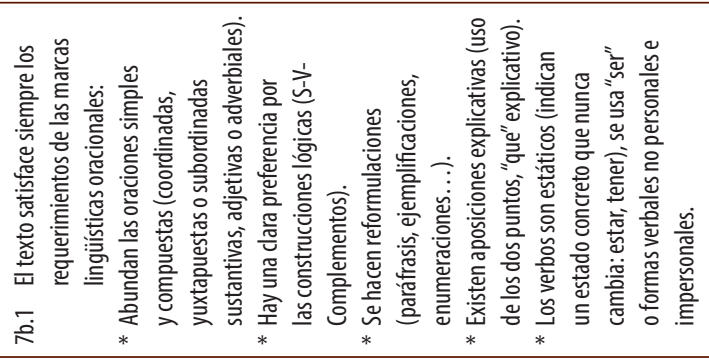 & 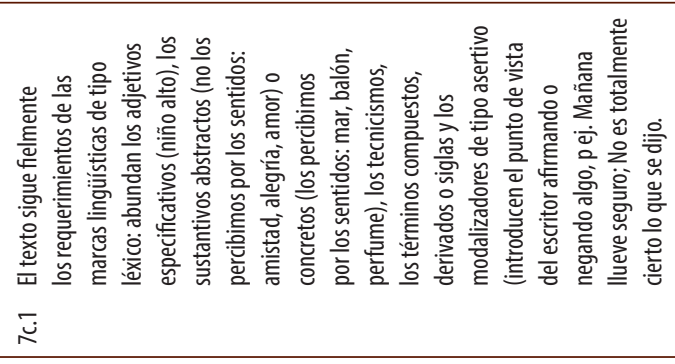 \\
\hline 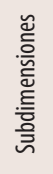 & 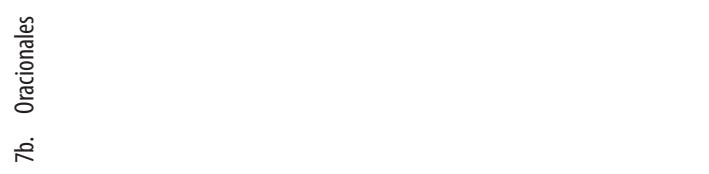 & 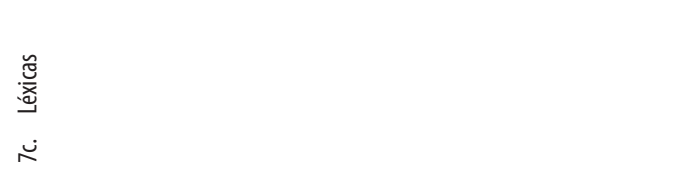 \\
\hline हूँ & & \\
\hline
\end{tabular}

